Bull. Chem. Soc. Ethiop. 2019, 33(2), 203-213.

ISSN 1011-3924

(c) 2019 Chemical Society of Ethiopia and The Authors

Printed in Ethiopia

DOI: https://dx.doi.org/10.4314/bcse.v33i2.2

\title{
LEVELS OF FLUORIDE IN BOTTLED SOFT DRINKS MARKETED IN ADDIS ABABA, ETHIOPIA
}

\author{
Ayfokru Kassahun and Bhagwan Singh Chandravanshi* \\ Department of Chemistry, College of Natural and Computational Sciences, Addis Ababa \\ University, P. O. Box 1176, Addis Ababa, Ethiopia
}

(Received December 9, 2018; Revised February 22, 2019; Accepted March 18, 2019)

\begin{abstract}
The main objective of this study was to determine the levels of fluoride in soft drinks (Coca Cola, Pepsi, Mirinda, Fanta and Sprite) marketed and widely consumed in Addis Ababa, Ethiopia. Three glass-bottled and three plastic-bottled soft drink samples from each brand were purchased randomly from Arat Kilo, Shiromeda and Shola supermarkets, kiosk and tea houses in Addis Ababa, Ethiopia. Levels of fluoride in the soft drink samples were determined by fluoride ion selective electrode. The method was validated by spiking test which provided percentage recoveries of fluoride in the soft drinks in the range $91-96 \%$. The mean fluoride concentration $(\mathrm{mg} / \mathrm{L})$ in the glass-bottled and plastic-bottled soft drink samples, respectively, were: Coca Cola $(0.03 \pm 0.01,0.06 \pm 0.01)$, Pepsi $(0.23 \pm 0.01,0.10 \pm 0.01)$, Mirinda $(0.21 \pm 0.02,0.09 \pm 0.01)$, Fanta $(0.03 \pm 0.01$, $0.05 \pm 0.01)$ and Sprite $(0.04 \pm 0.01,0.27 \pm 0.01)$. Pearson correlation showed that the levels of fluoride in the soft drinks were found to correlate positively with each other, which indicates similar source of main component (the water used for dilution). The low levels of fluoride in the soft drinks may not impose health risk in the adults but excessive consumption of soft drinks regularly by the children may result in dental fluorosis.
\end{abstract}

KEY WORDS: Fluoride, Coca cola, Pepsi, Mirinda, Fanta, Sprite

\section{INTRODUCTION}

Soft drinks are manufactured in Addis Ababa (Ethiopia) by different industrial companies. The soft drinks produced in Addis Ababa are Coca Cola, Pepsi, Mirinda, Fanta and Sprite. These soft drinks are the major ones widely consumed by the people in Ethiopia. The proportion of persons of all ages consuming soft drinks, the portion sizes and the number of servings have all increased [1]. With the frequent consumption of acidic, sugar rich soft drinks, children are at a higher risk of caries development [2]. This frequent conception of soft drinks causes dental enamel erosion [3]. Assessing the fluoride content of the soft drinks is important to prevent dental caries. Dental caries is one the most prevalent and widespread disease of the oral cavity affecting every age group [4]. Many preventive and curative measures have been documented in literature for dental caries [4, 5]. Since 1970, fluoride has become increasingly available for population with and without fluoridated drinking water and industrial beverages [6]. Conversely excessive systemic fluoride ingestion during tooth development can increase the risk of developing dental fluorosis. A total systemic fluoride exposure of $0.05-0.07 \mathrm{mg} / \mathrm{kg}$ body weight (bw)/day, in children, has been suggested as optimum for dental health benefits, whereas fluoride intakes of more than $0.1 \mathrm{mg} / \mathrm{kg}$ bw/day during the first five years of life can increase dental fluorosis risk [7]. Chronic high systemic fluoride exposure in adults ( $>6 \mathrm{mg} \mathrm{F} /$ day), over several years can lead to skeletal fluorosis; a debilitating conditions resulting in stiffness and pain in the joints $[8,9]$.

In Ethiopia carbonated soft drinks are produced and promoted the increased intake of soft drinks both in rural and urban areas. With the improving economic status, an increase in its population and swift changes in lifestyle including dietary behavior, the consumption of soft drinks has increased rapidly in recent years. Different brands of carbonated drinks available in

*Corresponding author. E-mail: bscv2006@yahoo.com

This work is licensed under the Creative Commons Attribution 4.0 International License 
the market have variable content of fluoride $[1,2,7]$. Studies have shown that nowadays, children take more beverages or carbonated drinks $[1,3,6,7]$. Generally, the production as well as consumption of carbonated beverages, has increased in Ethiopia. Some investigations have suggested that increased consumption of carbonated soft drinks are a form of systemic fluoridation and have been implicated as a risk factors for dental fluorosis in young children [10].

Therefore, there is a need to implement a comprehensive oral health preventive program to reduce oral disease burden. The World Health Organization (WHO) Global Oral Health Program promotes the "effective use of fluoride" as an important method to prevent dental caries [11].

The fluoride ion $\left(\mathrm{F}^{-}\right)$is not considered to be essential for human growth and development including for the development of healthy teeth and bones, and it is a potentially toxic ion at higher levels [12]. In the world hundreds of millions of people rely on drinking water with fluoride concentrations exceeding the present World Health Organization (WHO) guideline of $1.5 \mathrm{mg} / \mathrm{L}$ [13]. Long term use of drinking water with fluoride significantly above the WHO guideline value of $1.5 \mathrm{mg} / \mathrm{L}$ can have serious effects on health. Dental and skeletal fluorosis was registered by World Health Organization in 28 countries in 2006 due to the exposure of high fluoride concentration in drinking water. Among these countries, the most affected were India, Ethiopia and China [12]. In Ethiopian rift valley area an estimated more than seven million people are exposed to high levels of naturally occurring fluorides [14]. Daily intake of fluoride from drinking water, soft drinks and food are at risk of dental and skeletal fluorosis.

All natural water contains fluoride in different concentration such that sea water $(1 \mathrm{mg} / \mathrm{L})$, river and lakes contain less than $0.5 \mathrm{mg} / \mathrm{L}$. The ground water contains high or low concentration of fluoride depending on the nature of rocks and the occurrence of fluoride-bearing minerals. The concentration of fluoride in water is limited by the solubility of fluorite [15]. The concentration of fluoride increases in ground water in which cation exchange of sodium for calcium occurs [16]. Tap water, well water and spring water, are the common water supply source in Ethiopia both in the urban and rural areas.

The total exposure of fluoride depends on the contributions from various sources, such as drinking water, water-based beverages, foods, food supplements, toothpaste, and air [17-25]. Which means foods, beverages, carbonated soft drinks, and dental products are considered as the main sources of fluoride intake for children above one years of age [6].

The risks for dental fluorosis are fluoridated drinking water, fluoride toothpastes, fluoride supplements, industrialized food and beverages [5]. The primary adverse effects associated with chronic excess fluoride intake were enamel (dental) fluorosis in children up to age 8 years and skeletal fluorosis in children from age 9 years upwards and in adults [26]. Other than dental and skeletal fluorosis, fluoride can also cause for health problems affecting aorta, thyroid, lungs, kidneys, heart, pancreas, and brain as well as birth defects, genetic damage, and cancer [27, 28].

Food sources contain various concentrations of fluoride and are the largest contributor to fluoride exposure [17-25]. Soft drinks contribute the fluoride intake by the people who regularly consume Coca Cola, Pepsi, Mirinda, Fanta and Sprite [6, 29, 30]. However, there is no any study conducted to determine the fluoride content of industrially produced carbonated soft drinks widely consumed in Addis Ababa, Ethiopia. Therefore, the objectives of this study was (i) to determine the fluoride content of glass-bottled and plastic-bottled Coca Cola, Pepsi, Mirinda, Fanta and Sprite marketed in Addis Ababa city, Ethiopia, (ii) to compare the level of fluoride in Coca Cola, Pepsi, Mirinda, Fanta and Sprite in glass-bottled and plastic bottled, and (iii) to compare the levels of fluoride in bottled soft drink brands marketed in Addis Ababa to World Health Organization (WHO) guidelines. 


\section{EXPERIMENTAL}

\section{Apparatus and instruments}

Electronic balance (Adam Equipment, Model WL 3000, UK) was used for weighing chemicals for solution preparation. A pH/ISE meter (Orion model, EA 940 Expandable Ion Analyzer, USA) equipped with combination fluoride ion electrode (Orion Model 96-09, USA) was employed for the determination of fluoride in the samples and standard solutions. A pH/ION meter (HANNA instrument, HI 9025, Singapore) equipped with $\mathrm{pH}$ glass electrode was used to measure the $\mathrm{pH}$ value of sample solutions. Borosilicate volumetric flasks $(50,100,500$ and 1000 $\mathrm{mL}$ ) were used for preparation of both $5 \mathrm{M}$ sodium hydroxide solution and $1000 \mathrm{mg} / \mathrm{L} \mathrm{NaF}$ stock solution. Hot plate with magnetic stirrer was used for dissolution of the samples. Pipettes (Pyrex, USA) and micropipettes (Dragonmed 1-10 $\mu \mathrm{L}$, Shanghai, China) were used during measuring different volumes of sample solution and fluoride standard solutions.

\section{Chemicals and reagents}

The reagents used in this study were all of analytical grade. A $1000 \mathrm{mg} / \mathrm{L}$ fluoride standard stock solution was prepared by dissolving $2.21 \mathrm{~g}$ sodium fluoride $(99.0 \% \mathrm{NaF}, \mathrm{BDH}$ Chemicals, England) in $1000 \mathrm{~mL}$ of de-ionized water. Glacial acetic acid (100\%, Sigma-Aldrich Laborchemikalien, Germany), sodium chloride (Oxford Laboratory, Mumbai, India), tri-sodium citrate (BDH Chemicals, England), ethylene diamine tetra acetic acid (EDTA) (Scharlau Chemie S.A., Barcelona, Spain), and sodium hydroxide (Scharlau Chemie S.A., Sentmenat, Spain) were used to prepare the total ionic strength adjustment buffer (TISAB). The TISAB II was prepared by dissolving $58 \mathrm{~g}$ of sodium chloride, $57 \mathrm{~mL}$ of glacial acetic acid, $7 \mathrm{~g}$ of trisodium citrate and $2 \mathrm{~g}$ EDTA in $500 \mathrm{~mL}$ distilled water. The $\mathrm{pH}$ of this solution was adjusted to 5.3 with $5 \mathrm{M}$ sodium hydroxide and finally diluted to $1000 \mathrm{~mL}$ in a volumetric flask with diionized water.

\section{Sample collection}

Five brands of commercially available soft drink samples were purchased and collected randomly from Arat Kilo, Shiromeda and Shola super markets, Kiosk and tea house in Addis Ababa, Ethiopia. These soft drinks are typically supplied in three container formats including cans, paper/cardboard packages, glass-bottled and plastic-bottled but only two container formats are widely available to consumers in Addis Ababa, Ethiopia. Thus, fifteen glass-bottled and fifteen plastic-bottled soft drinks were purchased in this study. The glass-bottled contained 300 $\mathrm{mL}$ soft drink and the plastic-bottled contained $500 \mathrm{~mL}$ soft drink samples. The soft drinks from the glass-bottled samples were transferred to the clean and dried polyethylene bottles for easiness of sample handling. The commercially available brands which are Moha Beverage Industry Products and Coca Cola Beverage Industrial Products included Coca Cola, Pepsi, Mirinda, Fanta and Sprite for both glass-bottled and plastic-bottled soft drinks. All the samples were stored at room temperature $\left(22 \pm 2{ }^{\circ} \mathrm{C}\right)$ in the laboratory until analysis.

\section{Selected industrial soft drinks used in this study}

Coca Cola. The Coca Cola Company is an American corporation, and manufacturer, retailer, and marketer of non-alcoholic beverage concentrates and syrups [31]. Coca Cola is one of the Ethiopian industrial non-alcoholic beverages which are prepared from different ingredients. The ingredients are carbonated water, sugar (sucrose or high-fructose corn syrup depending on country of origin), caffeine, phosphoric acid, caramel color and natural flavorings [31]. 
Pepsi. Pepsi is a carbonated soft drink. This soft drink is produced by an American Food and Beverage Corporation. The ingredients are carbonated water, high fructose corn syrup, caramel color, phosphoric acid, caffeine, citric acid, and natural flavors [32].

Mirinda. Mirinda was originally produced in Spain. The ingredients are carbonated water, high fructose corn syrup, citric acid, modified food starch, potassium benzoate and potassium sorbate (to preserve freshness), ester gum, natural flavor, yellow 6, ascorbic acid and calcium disodium EDTA (to protect flavor) and sodium citrate [33].

Fanta. Fanta is a brand of fruit-flavored carbonated drinks created by the Coca Cola Company and marketed globally. The ingredients of Fanta are carbonated water, sugar, orange juice from concentrate $(3.7 \%)$, citrus fruit from concentrate $(1.3 \%)$, citric acid, vegetable extracts (carrot, pumpkin), sweeteners (acesulfame K, sucralose), preservative (potassium sorbate), malic acid, acidity regulator (sodium citrate), stabilizer (guar gum) and natural flavor [34].

Sprite. Sprite is colorless, caffeine free, lemon and lime flavored soft drink created by the Coca Cola Company. The sprite ingredients are carbonated water, high fructose corn syrup, citric acid, natural flavors, sodium citrate, sodium benzoate (to protect taste) [35].

\section{Sample preparation for analysis}

The soft drinks were firstly decarbonatedby by placing each sample in a plastic bottle loosely covered for $12 \mathrm{~h}$ and kept all the samples in at room temperature until the analysis was conducted.

\section{Determination of fluoride in samples}

The determination of fluoride in soft drinks (Coca Cola, Pepsi, Mirinda, Fanta and Sprite) using fluoride ion selective electrode was done by adding directly $5 \mathrm{~mL}$ of TISAB II to the $5 \mathrm{~mL}$ sample in $50 \mathrm{~mL}$ plastic beaker and taking the reading from calibrated fluoride ion selective electrode.

The calibration standard solutions of concentration $0.5,1,5,10$ and $20 \mathrm{mg} / \mathrm{L} \mathrm{F}^{-}$were prepared by serial dilution from the $1000 \mathrm{mg} / \mathrm{L}$ fluoride stock solution. An aliquot of $5 \mathrm{~mL}$ of de-ionized water and $5 \mathrm{~mL}$ of TISAB II were transferred in to $50 \mathrm{~mL}$ plastic beaker as a standard blank solution for the blank correction. An aliquot of $5 \mathrm{~mL}$ of each of standard solution was transferred in to five $50 \mathrm{~mL}$ plastic beaker separately and $5 \mathrm{~mL}$ of TISAB II solution was mixed with it to calibrate the fluoride ion selective ion electrode. The electrode potentials of these standard and blank solutions were measured by stirring the solution with magnetic stirrer constantly at room temperature with the fluoride ion selective electrode. A calibration curve was constructed by plotting the electrode potential as a function of fluoride concentration. The slope of the calibration curves was $-57.7 \mathrm{mV}$.

An aliquot of $5 \mathrm{~mL}$ of each sample solution was transferred in to $50 \mathrm{~mL}$ plastic beaker and 5 $\mathrm{mL}$ of TISAB II stirred constantly at room temperature and measured using fluoride ion selective electrode by direct potentiometery. The concentration of fluoride in the soft drink was measured three times for each type of soft drink.

\section{RESULTS AND DISCUSION}

\section{Fluoride electrode calibration}

A calibration curve was prepared by plotting the measured electrode potential of the calibration standard solution of concentrations $0.5,1,5,10$ and $20 \mathrm{mg} / \mathrm{L}$ as a function of fluoride 
concentration. The slope of the curve was $-57.7 \mathrm{mV} /$ decade which was found in the optimum range (57 to $60 \mathrm{mV} /$ decade). The slope value was nearest to the theoretical value of 59.2 $\mathrm{mV} /$ decade at room temperature. The correlation coefficient of calibration curve was, $\mathrm{r}=0.999$, which indicated good correlation between electrode potential and concentration of fluoride.

\section{Method validation}

In this study, the method validation was done by spiking experiments. The spiked samples were prepared by adding known concentration of the standard fluoride solution to $5 \mathrm{~mL}$ of the soft drink sample solution. The selected soft drink samples (Pepsi from glass-bottled and Sprite from plastic-bottled) was spiked with fluoride solution of which the fluoride content was equivalent to $25 \%, 50 \%$, or $100 \%$ of the fluoride content of the unspiked (original) samples. Fluoride concentrations in the un-spiked and spiked samples were determined. The recovery test results of fluoride in soft drinks samples are given in Table 1. Recoveries of spiked fluoride in the soft drink samples were found in the range $91-96 \%$ in the Pepsi and $91-94 \%$ in the Sprite. These recoveries are within the acceptable range. This recovery indicated that the method used for the fluoride determination in the soft drinks samples was precise and reliable.

Table 1. Recovery test results for fluoride in Pepsi from glass-bottled and Sprite from plastic-bottled samples.

\begin{tabular}{|l|c|c|c|c|}
\hline $\begin{array}{l}\text { Type of soft } \\
\text { drink }\end{array}$ & $\begin{array}{c}\text { Concentration of } \mathrm{F}^{-} \\
\text {in unspiked sample } \\
(\mathrm{mg} / \mathrm{L})\end{array}$ & $\begin{array}{c}\text { Amount of } \mathrm{F}^{-} \text {added } \\
\text { to the sample } \\
(\mathrm{mg} / \mathrm{L})\end{array}$ & $\begin{array}{c}\text { Concentration of } \\
\mathrm{F}^{-} \text {in spiked } \\
\text { sample }(\mathrm{mg} / \mathrm{L})\end{array}$ & Recovery (\%) \\
\hline Glass-bottled, & 0.23 & 0.057 & 0.285 & 96.5 \\
Pepsi & 0.23 & 0.115 & 0.336 & 92.2 \\
& 0.23 & 0.23 & 0.440 & 91.3 \\
\hline Plastic-bottled, & 0.27 & 0.067 & 0.331 & 91.0 \\
Sprite & 0.27 & 0.14 & 0.402 & 94.3 \\
& 0.27 & 0.28 & 0.530 & 92.9 \\
\hline
\end{tabular}

Levels of fluoride in soft drinks

There are only five brands of the most commonly consumed soft drinks marketed in Addis Ababa. Each of the five brands is available in glass and plastic-bottles. Therefore, a total of ten types of samples (five brands of glass-bottled and five brands of plastic-bottled soft drinks) were selected in this study. Three bottles of each sample were analyzed, i.e., a total of 30 samples $(5 \mathrm{x}$ $2 \times 3=30$ ). Factors such as seasonal variation, shelf-life, and in some cases regional distribution, etc., were not considered in this study.

The fluoride concentrations of the selected glass-bottled and plastic-bottled soft drinks (Coca Cola, Pepsi, Mirinda, Fanta and Sprite) collected from the markets of Addis Ababa are given in Table 2. The study showed that the highest and the lowest fluoride concentrations in glass-bottled Pepsi and Coca Cola and Fanta were 0.23 and $0.03 \mathrm{mg} / \mathrm{L}$ and in plastic-bottled Sprite and Fanta were 0.27 and $0.05 \mathrm{mg} / \mathrm{L}$, respectively. The concentrations of fluoride in glassbottled Coca Cola, Fanta and Sprite are similar and the concentration of fluoride in glass-bottled Pepsi and Mirinda are also almost the same.

The concentration of fluoride in plastic-bottled Coca Cola and Fanta are almost similar and concentration of fluoride in plastic-bottled Pepsi and Mirinda are also the nearly the same, but the plastic-bottled Sprite has highest fluoride concentration than the other plastic-bottled soft drinks. 
Table 2. Concentration (mean $\pm \mathrm{SD}, \mathrm{n}=3, \mathrm{mg} / \mathrm{L}$ ) of fluoride in carbonated soft drinks.

\begin{tabular}{|l|l|c|c|c|c|}
\hline $\begin{array}{l}\text { Type } \begin{array}{l}\text { Type } \\
\text { container }\end{array} \\
\text { Glass-bottled }\end{array}$ & Soft drink brand & Sample 1 & Sample 2 & Sample 3 & Mean \pm SD (mg/L) \\
\cline { 2 - 5 } & Coca Cola & 0.04 & 0.03 & 0.03 & $0.03 \pm 0.01$ \\
\cline { 2 - 6 } & Pepsi & 0.24 & 0.23 & 0.22 & $0.23 \pm 0.02$ \\
\cline { 2 - 6 } & Mirinda & 0.23 & 0.22 & 0.19 & $0.21 \pm 0.02$ \\
\cline { 2 - 6 } & Fanta & 0.04 & 0.03 & 0.03 & $0.03 \pm 0.01$ \\
\cline { 2 - 6 } & Sprite & 0.05 & 0.04 & 0.03 & $0.04 \pm 0.01$ \\
\hline \multirow{3}{*}{$\begin{array}{l}\text { Plastic- } \\
\text { bottled }\end{array}$} & Coca Cola & 0.07 & 0.07 & 0.06 & $0.06 \pm 0.01$ \\
\cline { 2 - 6 } & Pepsi & 0.11 & 0.10 & 0.09 & $0.10 \pm 0.01$ \\
\cline { 2 - 6 } & Mirinda & 0.06 & 0.05 & 0.08 & $0.09 \pm 0.01$ \\
\cline { 2 - 6 } & Fanta & 0.26 & 0.28 & 0.27 & $0.05 \pm 0.01$ \\
\cline { 2 - 6 } & Sprite & & & $0.27 \pm 0.02$ \\
\hline
\end{tabular}

Comparison of fluoride levels in glass-bottled and plastic-bottled soft drink samples

The mean fluoride concentrations in the glass-bottled and plastic-bottled soft drinks are shown in the Table 3. The order of fluoride concentrations in glass-bottled soft drinks is Pepsi > Mirinda $>$ Sprite $>$ Coca Cola and in the plastic-bottled soft drinks the order is Sprite $>$ Pepsi $>$ Mirinda $>$ Coca Cola $>$ Fanta, respectively. The distribution pattern of fluoride in glass-bottled and plastic-bottled soft drinks is different indicating the differences in the ingredients used in the two types of containers.

Table 3. Comparison of fluoride concentration (mean $\pm \mathrm{SD}, \mathrm{n}=3, \mathrm{mg} / \mathrm{L}$ ) in glass bottled and plastic bottled soft drinks.

\begin{tabular}{|l|c|c|c|c|c|}
\hline \multirow{2}{*}{$\begin{array}{l}\text { Type of } \\
\text { container }\end{array}$} & \multicolumn{5}{|c|}{$\mathrm{F}^{-}$concentration in soft drinks (mg/L) } \\
\cline { 2 - 6 } & Coca Cola & Pepsi & Mirinda & Fanta & Sprite \\
\hline Glass-bottled & $0.03 \pm 0.01$ & $0.23 \pm 0.01$ & $0.21 \pm 0.02$ & $0.03 \pm 0.01$ & $0.04 \pm 0.01$ \\
\hline Plastic-bottled & $0.06 \pm 0.01$ & $0.10 \pm 0.01$ & $0.09 \pm 0.01$ & $0.05 \pm 0.01$ & $0.27 \pm 0.01$ \\
\hline
\end{tabular}

A pair-wise t-test [36] at $\mathrm{p}=0.05$ probability level was applied to examine whether there is a significant difference between the glass-bottled and plastic-bottled soft drink of the particular brand. The t-test showed that there is no significant difference between the glass-bottled and plastic-bottled Coca Cola and Fanta brands of soft drink while the t-test showed that there is a significant difference between the glass-bottled and plastic-bottled Pepsi, Mirinda and Sprite brands of soft drinks. There are two reports in the literature comparing the levels of fluoride in glass-bottled and plastic-bottled Coca Cola soft drink. The study in Mexico [10] reported that there is no significant difference in the level of fluoride in the Coca Cola whether they are contained in the glass-bottle or plastic-bottle. In contrast to this, the study in the UK [38] showed significant difference in the level of fluoride in the Coca Cola contained in the glassbottle and plastic-bottle. While there is no any report in the literature comparing the levels of fluoride in glass-bottled and plastic-bottled soft drink of other four brands. The present study is the first comparative report on the levels of fluoride in glass-bottled and plastic-bottled soft drinks of four brands (Pepsi, Mirinda, Fanta and Sprite. There is no labeled value in any of the soft drink brands studied. Hence, no comparison has been made between the labeled values and experimentally determined values of fluoride in the soft drinks. Furthermore, there is no report in the literature on the regulation limiting fluoride levels in soft drinks. Hence no comparison has been made on the levels of fluoride found in the soft drinks and the regulation limiting fluoride levels in soft drinks by any organization or country. The fluoride levels found in the studied soft drinks are well below limiting levels recommended by the WHO guidelines for drinking water [13]. 
Comparison of fluoride levels in the soft drinks marketed in Ethiopia with the literature values

Many researchers have determined the concentration of fluoride in selected soft drinks in different parts of the world. The comparison of the fluoride concentration in the glass-bottled soft drinks of this study with the literature values is given in Table 4. The fluoride concentrations of Coca Cola reported in United Arab Emirates [30], China [29], Brazil [37], Mexico [10], UK [38], Sri Lanka [39] and India [40] are 0.08, 0.243, 0.092, 0.34, 0.26, 0.122 and $0.32 \mathrm{mg} / \mathrm{L}$, respectively, are higher than the fluoride concentration of glass-bottled Coca Cola of the present study.

The fluoride concentrations of Pepsi reported in United Arab Emirates [30], China [29], India [6], Sri Lanka [39] and India [40] are 0.09, 0.126, 0.22, 0.142, $0.21 \mathrm{mg} / \mathrm{L}$, respectively and are lower than $0.23 \mathrm{mg} / \mathrm{L}$ fluoride concentration in the glass-bottled Pepsi of the present study.

Table 4. Comparison of the fluoride concentrations in the glass-bottled soft drinks with the literature values.

\begin{tabular}{|c|c|c|c|}
\hline Glass-bottled soft drinks & Mean $\mathrm{F}^{-}$concentration $(\mathrm{mg} / \mathrm{L})$ & Country of origin & Reference \\
\hline Coca Cola & $\begin{array}{l}0.08 \\
0.243 \\
0.092 \\
0.34 \\
0.26 \\
0.122 \\
0.32 \\
0.03\end{array}$ & $\begin{array}{l}\text { UAE } \\
\text { China } \\
\text { Brazil } \\
\text { Mexico } \\
\text { UK } \\
\text { Sri Lanka } \\
\text { India } \\
\text { Ethiopia }\end{array}$ & $\begin{array}{l}{[30]} \\
{[29]} \\
{[37]} \\
{[10]} \\
{[38]} \\
{[39]} \\
{[40]} \\
\text { Present study }\end{array}$ \\
\hline Pepsi & $\begin{array}{l}0.09 \\
0.126 \\
0.22 \\
0.142 \\
0.21 \\
0.23 \\
\end{array}$ & $\begin{array}{l}\text { UAE } \\
\text { China } \\
\text { India } \\
\text { Sri Lanka } \\
\text { India } \\
\text { Ethiopia }\end{array}$ & $\begin{array}{l}30] \\
{[29]} \\
{[6]} \\
{[39]} \\
{[40]} \\
\text { Present study }\end{array}$ \\
\hline Mirinda & $\begin{array}{l}0.05 \\
0.28 \\
0.198 \\
0.27 \\
0.21 \\
\end{array}$ & $\begin{array}{l}\text { UAE } \\
\text { India } \\
\text { Sri Lanka } \\
\text { India } \\
\text { Ethiopia }\end{array}$ & $\begin{array}{l}{[30]} \\
{[6]} \\
{[39]} \\
{[40]} \\
\text { Present study }\end{array}$ \\
\hline Fanta & $\begin{array}{l}0.33 \\
0.109 \\
0.30 \\
0.03\end{array}$ & $\begin{array}{l}\text { India } \\
\text { Sri Lanka } \\
\text { India } \\
\text { Ethiopia }\end{array}$ & $\begin{array}{l}{[6]} \\
{[39]} \\
{[40]} \\
\text { Present study }\end{array}$ \\
\hline Sprite & $\begin{array}{l}0.29 \\
0.098 \\
0.26 \\
0.04\end{array}$ & $\begin{array}{l}\text { India } \\
\text { Sri Lanka } \\
\text { India } \\
\text { Ethiopia }\end{array}$ & $\begin{array}{l}{[6]} \\
{[39]} \\
{[40]} \\
\text { Present study }\end{array}$ \\
\hline
\end{tabular}

The fluoride concentration of Mirinda reported in India $[6,40]$ is higher than that of the glass-bottled Mirinda of present study and the fluoride concentration of Mirinda reported in United Arab Emirates [30] and Sri Lanka [39] is lower than that of the present study. Also the fluoride concentration of Fanta reported in India $(0.33 \mathrm{mg} / \mathrm{L})[6]$ and $(0.30 \mathrm{mg} / \mathrm{L})[40]$ and in Sri Lanka $(0.109 \mathrm{mg} / \mathrm{L})[39]$ and fluoride concentration in reported in Sprite in India $(0.29 \mathrm{mg} / \mathrm{L})$ [6] and $(0.26 \mathrm{mg} / \mathrm{L})[40]$ and in Sri Lanka $(0.098 \mathrm{mg} / \mathrm{L})$ are higher than that of the glass-bottled Fanta and Sprite of the present study.

There are only two reports $[10,38]$ in the literature on the fluoride levels in plastic-bottled Coca Cola and only one report on the fluoride levels in plastic-bottled Pepsi [38]. The comparison of the fluoride concentration in the plastic-bottled Coca Cola and Pepsi soft drinks 
of this study with the literature values is given in Table 5. The fluoride concentration of Coca Cola reported in Mexico [10] is $0.37 \mathrm{mg} / \mathrm{L}$ and it is higher than the fluoride level $(0.06 \mathrm{mg} / \mathrm{L})$ of the present study, while the fluoride level of the present in study is similar to that in the UK [38]. The fluoride concentration of Pepsi reported in the UK [38] is $0.19 \mathrm{mg} / \mathrm{L}$ and it is higher than that of the present study $(0.10 \mathrm{mg} / \mathrm{L})$. There is no any report in the literature on fluoride level in other three brand of soft drink (Mirinda, Fanta and Sprite). Therefore, no comparison has been made on the level of fluoride in the plastic-bottled Mirinda, Fanta and Sprite soft drink of this study with the literature values.

Table 5. Comparison of the fluoride concentrations in the plastic bottled soft drinks with values in the literature.

\begin{tabular}{|l|l|l|l|}
\hline Plastic bottled soft drinks & Mean F concentration $(\mathrm{mg} / \mathrm{L})$ & Contry of origin & Reference \\
\hline Coca Cola & 0.37 & Mexico & {$[10]$} \\
& 0.06 & UK & {$[38]$} \\
& 0.06 & Ethiopia & Present study \\
\hline Pepsi & 0.19 & UK & {$[38]$} \\
& 0.10 & Ethiopia & Present study \\
\hline
\end{tabular}

Pearson correlation

The Pearson correlation shows weak, moderate or strong relationship among variables in the positive or negative direction [36]. The correlation of levels of fluoride in the soft drinks among different brands in the glass bottled and plastic bottled are given in Table 6 and 7 . The levels of fluoride in the glass-bottled soft drinks have strong positive correlation among each other. The levels of fluoride in plastic-bottled soft drinks also have strong positive correlation among each other except Sprite with Pepsi and Fanta. Sprite showed moderate negative correlation with Pepsi and Fanta. This may be due to differences in the ingredients used in the two soft drinks. In general, Pearson correlation showed positive correlation among each other, which indicates similar source of main ingredient, i.e., the water used for dilution.

Table 6. Pearson correlations of fluoride levels glass bottled soft drinks.

\begin{tabular}{|l|c|c|c|c|c|}
\hline Soft drink & Coca Cola & Pepsi & Mirinda & Fanta & Sprite \\
\hline Coca Cola & 1.000 & 0.866 & 0.693 & 1.000 & 0.866 \\
\hline Pepsi & 0.866 & 1.000 & 0.961 & 0.866 & 1.000 \\
\hline Mirinda & 0.693 & 0.961 & 1.000 & 0.693 & 0.961 \\
\hline Fanta & 1.000 & 0.866 & 0.693 & 1.000 & 0.866 \\
\hline Sprite & 0.866 & 1.000 & 0.961 & 0.866 & 1.000 \\
\hline
\end{tabular}

Table 7. Pearson correlations of fluoride levels plastic bottled soft drinks.

\begin{tabular}{|l|c|c|c|c|c|}
\hline Soft drink & Coca Cola & Pepsi & Mirinda & Fanta & Sprite \\
\hline Coca Cola & 1.000 & 0.866 & 1.000 & 0.866 & 0.000 \\
\hline Pepsi & 0.866 & 1.000 & 0.866 & 1.000 & -0.500 \\
\hline Mirinda & 1.000 & 0.866 & 1.000 & 0.866 & 0.000 \\
\hline Fanta & 0.866 & 1.000 & 0.866 & 1.000 & -0.500 \\
\hline Sprite & 0.000 & -0.500 & 0.000 & -0.500 & 1.000 \\
\hline
\end{tabular}

\section{CONCLUSION}

In this study the levels of fluoride were determined in both glass-bottled and plastic-bottled five different brands of soft drinks widely consumed in Ethiopia. The levels of fluoride in glass- 
bottled soft drinks were found in the range of $0.03-0.23 \mathrm{mg} / \mathrm{L}$ while the fluoride levels in the plastic-bottled soft drinks were in the range $0.05-0.27 \mathrm{mg} / \mathrm{L}$. Fluoride levels in Pepsi and Mirinda in glass-bottled beverages were much higher than in plastic-bottled soft drinks, while the fluoride levels in Coca Cola, Fanta and Sprite were higher in the plastic-bottled soft drinks than in glass-bottled soft drinks. The levels of fluoride in glass-bottled Pepsi and Mirinda and plastic-bottled Sprite were much higher than the others. The levels of fluoride are relatively lower in the Ethiopian soft drinks than in the Indian soft drinks while the fluoride levels in Ethiopian soft drinks are comparable to United Arab Emirates soft drinks. The fluoride levels in the soft drinks are low and hence safe for human consumption unless children consume excessive amounts of soft drinks regularly. Pearson correlation showed that the levels of fluoride in the soft drinks correlate positively with each other which indicates similar source of main ingredient (the water used for dilution). This study provides information on the content of fluoride in industrially produced carbonated soft drinks widely consumed in Addis Ababa, Ethiopia and provide base-line data for further studies.

\section{ACKNOWLEDGEMENTS}

The authors are thankful to the Department of Chemistry, Addis Ababa University, Addis Ababa, Ethiopia for providing laboratory facilities. Ayfokru Kassahun is thankful to the Ministry of Education, Ethiopia, for sponsoring his study.

\section{REFERENCES}

1. Nielsen, S.J., Popkin, B.M. Changes in beverage intake between 1977 and 2001. Am. J. Prev. Med. 2004, 27, 205-210.

2. Tahmassebi, J.F.; Duggal, M.S.; Malik-Kotru, G.; Curzon, M.E.J. Soft drinks and dental health: A review of the current literature. J. Dent. 2006, 34, 2-11.

3. Cheng, R.; Yang, H.; Shao, M.-Y.; Hu, T.; Zhou, X.-D. Dental erosion and severe tooth decay related to soft drinks: a case report and literature review. J. Zhejiang Univ. Sci. B 2009, 10, 395-399.

4. Philip, N.; Suneja, B.; Walsh, L.J. Ecological approaches to dental caries prevention: paradigm shift or shibboleth? Caries Res. 2018, 52, 153-165.

5. Alvarez, J.A.; Rezende, K.M.P.C.; Marocho, S.M.S.; Alves, F.B.T.; Celiberti, P.; Ciamponi, A.L. Dental fluorosis: Exposure, prevention and management. Med. Oral Patol. Oral Cir. Bucal. 2009, 14, E103-E107.

6. Bansal, M.; Gupta, N. Estimation of fluoride levels in varies commercially available Carbonated soft drinks in Chandigarh city, India. J. Indian Assoc. Public Health Dent. 2015, 13, 514-516.

7. Burt, B.A. The changing patterns of systemic fluoride intake. J. Dent. Res.1992, 71, 12281237.

8. Krishnamachari, K.A. Skeletal fluorosis in humans: A review of recent progress in the understanding of the disease. Prog. Food Nutrition Sci. 1986, 10, 279-314.

9. Kurdi, M.S. Chronic fluorosis: The disease and its anaesthetic implications. Indian J. Anaesth. 2016, 60, 157-162.

10. Jimenez-Farfan, M.D.; Hernandez-Guerrero, J.C.; Loyala-Rodriguez, J.P.; Ledesma-Montes, C. Fluoride content in bottled water juices and carbonate soft drinks, in Mexico city, Mexico. Int. J. Pediatr. Dent. 2004, 14, 260-266.

11. Petersen, P.E.; Lennon, M.A. Effective use of fluoride for the prevention of dental caries in the 21st century: The WHO approach. Community Dent. Oral Epidemiol. 2004, 32, 319-321. 
12. Scientific Committee on Health and Environment Risk (SCHER) Opinion of critical review of any new evidence on the hazard profile, health effects, and human exposure to fluoride and the fluoridating agents of drinking water. Brussels, Belgium: Directorate General for Health and Consumers, European Commission, 2011.

13. World Health Organization Guidelines for Drinking Water Quality: Third Education Incorporating the First and the Second Agenda, Volume one, Recommendations, World Health Organization: Geneva; 2008.

14. Tekle-Haimanot, R. Study of Fluoride and Fluorosis in Ethiopia with Recommendation on Appropriate Defluoridation Technologies, A UNICEF sponsored consultancy: Addis Ababa, Ethiopia; 2005.

15. Fawell, J.; Bailey, K.; Chilton, J.; Dahi, E.; Fewtrell, L.; Magara, Y. Fluoride in Drinking Water, World Health Organization and IWA Publishing, Inc.: London; 2006; pp. 15-35.

16. Edmunds, W.M.; Smedley, P.L. Ground water geochemistry and health: An overview. In: Environmental Geochemistry and Health, Appleton, J.D.; Fuge, R.; McCall, G.J.H. (Eds.), Geological Society Special Publication 1996, 113, 91-105.

17. Zerabruk, S.; Chandravanshi, B.S.; Zewge, F. Fluoride in black and green tea (Camellia sinensis) infusions in Ethiopia: Measurement and safety evaluation. Bull. Chem. Soc. Ethiop. 2010, 24, 327-338.

18. Tegegne, B.; Chandravanshi, B.S.; Zewge, F. Fluoride levels in commercially available rice in Ethiopia. Bull. Chem. Soc. Ethiop. 2013, 27, 179-189.

19. Embiale, A.; Chandravanshi, B.S.; Zewge, F. Levels of fluoride in the Ethiopian and imported black tea (Camellia sinensis) infusions prepared in tap and fluoride-rich natural waters. Int. J. Food Eng. 2014, 10, 447-455.

20. Mustofa, S.; Chandravanshi, B.S.; Zewge, F. Levels of fluoride in staple cereals and legumes produced in selected areas of Ethiopia. SINET: Ethiop. J. Sci. 2014, 37, 43-52.

21. Asayehegn, G.; Chandravanshi, B.S.; Zewge, F. Fluoride level in tef [Eragrostis tef (Zucc.) Trotter] and enjera and its health implications. SINET: Ethiop. J. Sci. 2014, 37, 53-62.

22. Syume, M.; Chandravanshi, B.S. Levels of fluoride in niger seed (Guizotia abyssinica) cultivated in Ethiopia and Eritrea. Fluoride 2015, 48, 259-265.

23. Nigus, K.; Chandravanshi, B.S. Levels of fluoride in widely used traditional Ethiopian spices. Fluoride 2016, 49, 165-177.

24. Belete, Y.; Chandravanshi, B.S.; Zewge, F. Levels of the fluoride ion in six traditional alcoholic fermented beverages commonly consumed in Ethiopia. Fluoride 2017, 50, 79-96.

25. Dagnaw, L.A.; Chandravanshi, B.S.; Zewge, F. Fluoride content of leafy vegetables, irrigation water and farmland soil in rift valley and non rift valley areas of Ethiopia. Fluoride 2017, 50, 409-429.

26. Institute of Medicine Dietary Reference Intakes for Calcium, Phosphorus, Magnesium, Vitamin D and Fluoride, National Academies Press: Washington DC; 1997.

27. Yiamouyiannis, J. Fluoride is the silent killer. African Traditional Herbal Research Clinic Newsletter 2011, 6, 8-16.

28. Augustine, A.; Anitha, P. Health risk from fluoride exposure of a population in selected areas of Tamil Nadu, South India. Department of Chemistry, Gandhigram Rural Institute Deemed University 2013, 2, 75-86.

29. Liu, Y.; Maguira, A.; Tiangui, G.; Yanguo, S.; Zohoori, F.V. Fluoride concentrations in a range of ready-to-drink beverages consumed in Heilongjiang Provence, north-east China. Nutr. Health 2017, 23, 25-32.

30. Walia, T.; Fanas, S.A.; Akbar, M.; Eddin, J.; Adnan, M. Estimation of fluoride concentration in drinking water and common beverages in United Arab Emirates (UAE). Saudi Dent. J. 2017, 29, 117-122.

31. Coca Cola (2018). The Coca Cola brands. Retrieved, 30 August, 2018. Available at: https://www.coca-colacompany.com/brands/coca-cola. 
32. Pepsi (2018). 2018 - Pepsi Co, parent company of Pepsi. Retrieved, 30 August, 2018. Available at: www.pepsico.com.

33. Mirinda (2018). 2018 - Pepsi Co, parent company of Pepsi. Retrieved, 30 August, 2018. Available at: www.pepsico.com/live/content/topic/Mirinda.

34. Fanta (2018). The Coca Cola Company/brands/fanta. Retrieved, 30 August, 2018. Available at: https://www.coca-colacompany.com/brands/fanta.

35. Sprite (2018). The Coca Cola Company/brands/sprite. Retrieved, 30 August, 2018. Available at: https://www.coca-colacompany.com/brands/sprite.

36. Miller, J.N.; Miller, J.C. Statistics and Chemometrics for Analytical Chemistry, 5th ed., Pearson Practice Hall: England; 2005; pp 55-72.

37. Lodi, C.S.; Ramires, I.; Pessan, J.P.; Neves, L.T.D.; Buzalaf, M.A.R. Fluoride concentrations in industrialized beverages consumed by children in the city of Bauru, Brazil. J. Appl. Oral. Sci. 2007, 15, 209-212.

38. Omid, N.; Zohoori, F.V.; Kometa, S.; Maguire, A. Erosive characteristics and fluoride content of cola-type drink. British Dent. J. 2016, 220, 349-55.

39. Ratnayake, N.; Ekanayake, L.; Gangadhara, B. Properties of carbonated beverages sold in Sri Lanka: Implications for tooth erosion. Sri Lanka Dent. J. 2011, 41, 09-16.

40. Thippeswamy, H.M.; Kumar, N.; Anand, S.R.; Prashant, G.M.; Chandu, G.N. Fluoride content in bottled drinking waters, carbonated soft drinks and fruit juices in Davangere city, India. Indian J. Dent. Res. 2010, 21, 528-530. 